\title{
Çayın Kardiyovasküler Hastalıklar Üzerine Etkisi
}

\section{Erkan POLAT ${ }^{* 1}$ (D) Ayşe Demet KARAMAN² ${ }^{2}$, Serdal ÖĞÜ̈T}

${ }^{1}$ Bursa Yenişehir Devlet Hastanesi, Bursa

${ }^{2}$ Aydın Adnan Menderes Üniversitesi, Ziraat Fakültesi, Aydın

${ }^{3}$ Aydın Adnan Menderes Üniversitesi, Sağlık Bilimleri Fakültesi, Aydın

Öz: Camellia sinensis yapraklarının toplanarak çeşitli işlemler yapıldıktan sonra elde edilen çay, dünyada sudan sonra en çok tüketilen içecektir. Her zaman yeşil kalan çay, yağmurlu ve ılık iklimde yetişen bir bitkidir. Çayın türleri, koparılan yaprakların farklı işlemlerden geçirilmesiyle elde edilir. Bu işlemler; fermente olan (siyah çay) ile fermente olmayanlar (beyaz ve yeşil çay) ve yarı fermente olanlar (oolong çayı) olmak üzere üç gruba ayrılır. Her çay türü, yaprakların nasıl işlendiğine, olgunlaşma sürecine, coğrafi bölgeye ve tarımsal uygulamalara bağlı olarak ayrı bir bileşime sahiptir. Yapılan epidemiyolojik çalışmalar, çay ve bileşenlerinin özellikle flavonoidlerin, kardiyovasküler sistem üzerinde koruyucu etkileri olduğunu göstermiştir. Theaflavinler, thearubiginler gibi polifenoller ve özellikle kateşinler gibi bileşenler, antioksidan etkilerden sorumludur. Bu nedenle çay hipokolesterolemik, antiaterosklerotik, antibakteriyel, antioksidatif, antimutajenik, antikarsinojenik, antianjiyojenik, apoptotik gibi özellikleri içerir. Yapılan çalışmalar, günde 6-10 fincan (yaklaşık 960-1600 ml) çay tüketiminin kronik hastalıklardaki riski önemli oranda azalttığını göstermektedir. Çay içeriğindeki antioksidanların reaktif türlere karşı endojen savunma açııından yetersiz kaldığında oksidatif stres kaynaklı hastalıkların başlangııını ve ilerlemesini engellemede büyük bir role sahip olduğu belirtilmiştir. Ayrıca çaydaki antioksidanların, kardiyovasküler hastalıklara karşı koruyucu etkileri ile ilgili yeni bulguları araştırmak amaçlanmıştır.

Anahtar Kelimeler: antioksidan, polifenol, flavanoid, kataşin

\section{The Effect of Tea on Cardiovascular Diseases}

\begin{abstract}
Tea, obtained after done various operations by gathering the leaves of Camellia sinensis, is the most consumed drink in the world after water. The tea being always green is a plant that grows in rainy and warm climate. The types of tea are obtained by passed from different operations of plucked leaves. These processes are divided into three groups impending fermented (black tea) and non-fermented (white and green tea) and semi-fermented (oolong tea). Each type of tea has a different composition by depending on how the leaves are processed, the maturation process, geographical area and agricultural practices. Made epidemiological studies have shown that tea and its components, especially flavonoids, have protective effects on the cardiovascular system. Theaflavins, polyphenols such as thearubigins, especially components such as catechins, are responsible for the antioxidant effects. Therefore tea, contains properties such as hypocholesterolemic, antiatherosclerotic, antibacterial, antioxidative, antimutagenic, anticarcinogenic, antiangiogenic, apoptotic. Studies show that tea consumption of 6-10 cups (approximately 960-1600 ml) a day significantly reduces the risk of chronic diseases. It was stated that antioxidants in tea content have a major role in preventing the onset and progression of oxidative stress-induced illnesses when they are inadequate in terms of endogenous defense against reactive species. In addition, it was aimed to investigate new findings about the protective effects of antioxidants in tea against cardiovascular illnesses.
\end{abstract}

Keywords: antioxidant, polyphenol, flavonoid, catechins

\section{GíRiş}

Latince adıyla Camellia sinensis olan çay, dünya nüfusunun üçte ikisinde sudan sonra en fazla tüketilen içecektir (Henning ve ark., 2003). Yeşil çay yapraklarının oksidasyonundan yapılan siyah çay, dünya çay üretiminin \%80'ine eşittir (Graham, 1992). Çay üretimin büyük kısmı Çin, Sri Lanka, Tayvan, Japonya olmak üzere yaklaşık 30 ülkede yapılmaktadır. Türkiye' de de çay üretim ve tüketimi yaygındır (Cooper ve ark., 2005; Graham, 1992). Ülkemizde üretimi Gürcistan sınırı batısında Fatsa'ya kadar olan Doğu Karadeniz Bölgesinde yapılmaktadır (Sarı, 2010). Uluslararası Çay Komitesi (The International Tea Committee-ITC) 2019 yılında Dünya çay üretiminin 2018 için $5,896,644$ ton, bunun 252,000 tonunun Türkiye'de üretildiğini bildirmiştir (ITC, 2019). Ülkemizde çay üretiminin $\% 98$ 'ini siyah çay, $\% 2$ 'si yeşil çay ve diğer çaylar oluşturmaktadır. Ayrıca son yıllarda beyaz çay da üretilmeye başlanmıştır. Fakat toplanması zahmetli ve oldukça kısa bir hasat dönemi olduğu için ülkemizde üretimi oldukça azdır (ÇAYKUR, 2011).

Dünya üzerinde çay tüketim şekilleri farklılık göstermektedir. Koparılan çay yapraklarına farklı işlemler uygulanarak çay ürünleri elde edilir. Çin ve Japonya gibi Uzakdoğu ülkelerinde yeşil çay, Hindistan ve batısında kalan ülkelerde siyah çay tüketimi yaygındır (Sumpio ve ark., 2006). Oolong çayı ise Tayvan ve Güneydoğu Çin'de tüketilmektedir (Katiyar ve ark., 1992).

Çayın sağlık üzerinde yararları olabileceği, kanser ve

Sorumlu Yazar: polaterkn@gmail.com

Geliş Tarihi: 12Aralık 2019

Kabul Tarihi: 4 Mayıs 2020 
kardiyovasküler hastalık riskini azalttığı tartışılmaktadır. Çayın hastalık riskini azalttığına dair çalışmalar çayın içeriğinde bulunan flavonidlere ve bu bileşenlerin antioksidan etkileri ile açıklanmaktadır (Hollman ve ark., 1999).

\section{Çay Türleri ve İçerikleri}

Çayların işlenme şekilleri değiştikçe elde edilen çay farklı olmaktadır. Çay fermantasyona uğramadan yeşil çay, yarı fermente edilerek oolong çayı ve tam fermantasyonla siyah çay elde edilir (Vinson ve ark., 2004). Beyaz çay ise bu çaylar arasında en az işlem görmüş çay olmakla birlikte Çin'in Fujian eyaletinde sadece bahar mevsiminde hasat edilen bir çaydır (Hilal and Engelhardt, 2007). Beyaz çay, Camellia sinensis bitkisinden üretilen çaylarda en düşük üretime sahiptir. Tomurcuklar demlenen beyaz çaya açık gri renk ve hafif tatlı bir aroma vermektedir (Üstün ve Demirci, 2013). Beyaz çayın rengi yaprakların klorofil üretimini azaltmak için yaprakları güneş ışı̆̆ından korunarak elde edilir (Chang, 2015).

Yeşil ve siyah çayın insan sağlığı üzerinde çok yararlı olduğu bilinmekle birlikte beyaz çay bu çaylar arasında en yüksek antioksidan içeriğine sahiptir. Antioksidanlar, DNA yapısına zarar vererek vücuda zarar veren ve yaşlanmayı hızlandıran serbest radikalleri etkisiz hale getirir. Beyaz çay yüksek miktarda kateşin özellikle de EGCG (Epigallokateşin Gallat) içermektedir. Çayda yüksek miktarda bulunan antioksidanlar, kanser hücrelerinin büyümesini engeller, antibakteriyel, antiviral etki göstermektedir (ÇAYKUR, 2011).

Yeşil çay, bitkinin tepesinde bulunan tomurcuğu ve onun altında bulunan iki yaprak taze hasat edilir ve okside olmamaktadır (Çelik, 2006; Tosun, 2012).

Çay yapraklarının ezilmesiyle polifenol oksidaz enzimi ortaya çıkar ve oksidasyona uğrayarak siyah çay oluşur (Yang and Landau, 2000). Siyah çayın üretim sürecinde soldurma, kıvırma ve kurutma işlemleri yapılır. Kıvırma işlemi sırasında çay hücrelerinin yapısı bozulur ve fermantasyon süreci başlar. Siyah çayın lezzetinin kurutma işleminde oluştuğu gözlenmiştir (Altuğ ve Elmacı, 1998). Siyah çayın elde edilme sürecinde kullanılan teknoloji değişiklik gösterdiği için içeriğini betimlemek zordur (Henning ve ark., 2003). Oolong çayı ise, kısmen fermente edilerek yeşil ve siyah çayın karakteristikliğine sahiptir (Haslam, 2003). Çayların işleme evreleri, Şekil 1'de verilmiştir (Hilal and Engelhardt, 2007).

Çaylar sebze veya meyve olarak sınıflandırılmaz. Fakat sebze ve meyvelerde bulunan flavonoidler bakımından zengin oldukları için başta koroner kalp hastalıkları, obezite ve çeşitli kanser türleri üzerinde koruyucu etki göstermektedirler (Langley and Simon, 2000). Çay, çoğunlukla polifenol olmak üzere yaklaşık 400 biyoaktif bileşen içermektedir. Bu bileşikler; alkoloidler, proteinler, karbonhidratlar, uçucu organik bileşikler, polifenoller ve eser miktarda elementlerdir (Çelik, 2006; Mahmood ve ark., 2010; McKay and Blumberg 2002; Namita et al, 2012).

Polifenol grubunda kateşinler ve bunlardan da epigallokateşin yoğun şekilde bulunmaktadır. Ayrıca epikateşin(EC), epikateşin gallat(ECG) ve kateşin(C) farklı miktarlarda bulunmaktadır (Cooper ve ark., 2005). Theaflavinler(TF) ve thearubilginler(TB) kateşinleri siyah çaya rengini ve buruk tadını vermektedir (Leung ve ark., 2001).

Yapılan çalışmalar toplam polifenol, toplam kateşin, kafein, gallik asit, teobromin, EGC, ECG ve EGCG konsantrasyonları arasında farklılık olduğunu göstermiştir (Hilal and Engelhardt, 2007; Santana ve ark., 2001). Atalay ve Erge (2017) yürüttükleri çalışmada ABTS (Troloks Eşiti Antioksidan Kapasite) Yöntemi ile çayların antioksidan aktivitelerini şu şekilde bulmuştur; yeşil çay $9.7 \mu \mathrm{M} \mathrm{TE} / \mathrm{g}$, beyaz çay $8.45 \mu \mathrm{M} \mathrm{TE} / \mathrm{g}$, siyah çay da ise $2.75 \mu \mathrm{M} \mathrm{TE} / \mathrm{g}$ olarak bulmuşlardır. DPPH (Difenil-1-pikrihidrazil radikal söndürücü kapasite yöntemiyle de benzer sonuçlara

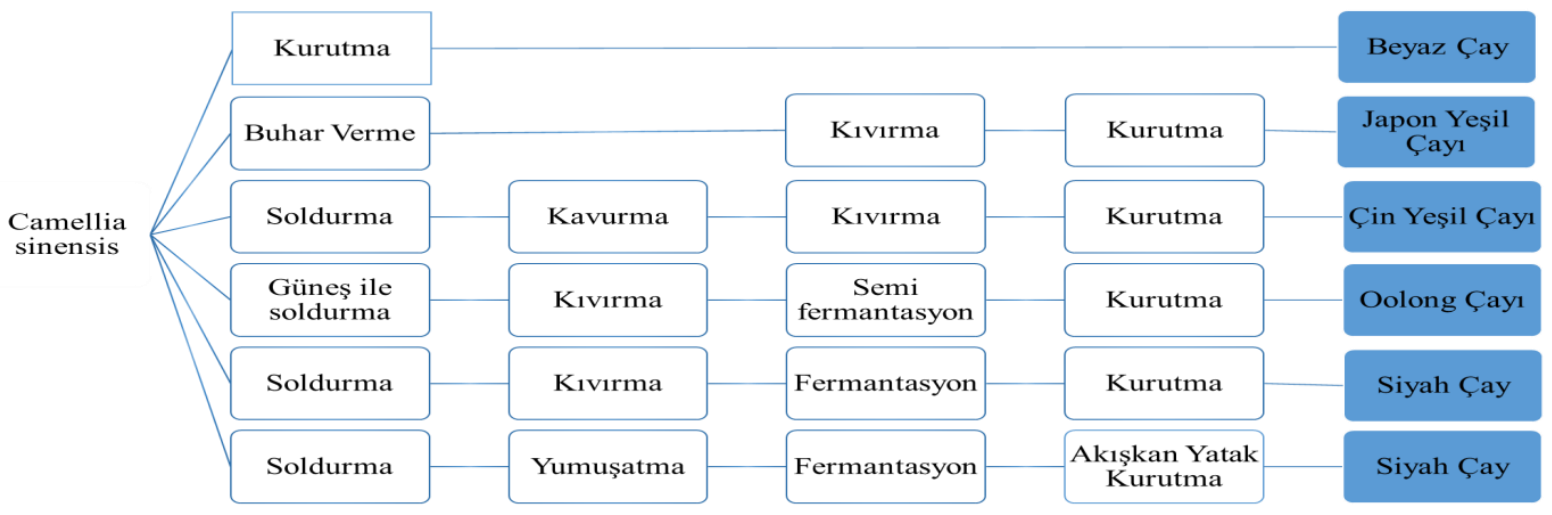

Şekil 1. Çay bitkisine uygulanan işlemlerin şematik gösterimi (Hilal and Engelhardt, 2007) 
ulaşmışlardır. Carloni ve ark. (2013) yürüttükleri çalışmada çayların antioksidan aktivitelerini sırasıyla yeşil çay, beyaz çay, siyah çay olarak bulmuşlardır. Ayrıca yeşil çayın siyah çaya oranla daha fazla oranda kateşin içerdiği ve kateşin miktarının antioksidan aktivitesi ile pozitif korelasyon gösterdiğini bildirmişlerdir. Farklı çayların fenolik madde içeriği ve antioksidan aktivitesi, Çizelge $1^{\prime}$ 'de belirtilmiştir (Carloni ve ark., 2013).

Bir fincan çay ( 1 ila 3 dakika boyunca sıcak suda demlenmiş 2 g çay yaprağı) 150-200 mg flavonoid sağlamaktadır (Hodgson, 2008). Langley ve Simon (2000), yürüttüğü çalışmada bireylerin günlük antioksidanların \%35-45'ini çay flavonoidleri aracılığıyla karşıladığını, demlenme sırasında suyun sıcaklığının artması deme antioksidan geçişini arttığını bildirmiştir.

Çay içeriğinde bulunun polifenollerin 3/4'ü flavanol, flavanollerin ise \%60-70'i EGCG'den oluşmaktadır (Katiyar and Hasan, 1997)

\section{Çay ve Kardiyovasküler Hastalık iliş̧kisi}

Kalbi besleyen ve çevreleyen damarla ilgili hastalıklar, koroner kalp hastalığı veya koroner arter hastalığı (KAH)
POLAT E, KARAMAN AD, ÖĞÜT S olarak adlandırılır. Koroner kalp hastalığına inmenin eklenmesi kalp ve damar hastalıkları (KDH) olarak adlandırılır. Okside olmuş lipoprotinler kalp damarlarındaki plaklarda görülmektedir. Çay içeriğinde bulunan polifenolik bileşikler kronik hastalıklardan koruyucu etki göstermektedir (Henning ve ark., 2003).

Çay tüketimi, KDH'larında LDL oksidasyonunu engelleyerek koruyucu etki göstermektedirler (Hodgson ve ark., 2000). Çay içeriğindeki flavonoidler serbest radikalleri tutarak siklooksigenaz lipoksigenaz enzimlerini inhibe eder. Böylece lipit peroksidasyonunu önleyerek aterosklerotik plakların büyümesini engeller ve abtitrombotik etkisiyle aterosklerozisten korumaktadır (Formica and Regelson, 1995).

Çayın kardiyovasküler hastalıklarda ve birçok hastalık üzerinde özellikle diyabet, obezite ve kanser üzerine etkisi olduğu çalışmalarla desteklenmektedir. Çay tüketiminin insan sağlığı üzerindeki etkisi, Çizelge 2'de verilmiştir (Formica and Regelson, 1995; Hertog ve ark., 1993; Hodgson ve ark., 2002).

Çizelge 1. Farklı çayların fenolik madde içerik ve dağılımı (Carloni ve ark., 2013)

\begin{tabular}{|c|c|c|c|c|c|c|}
\hline \multicolumn{3}{|c|}{+2} & Beyaz çay & Yeşil Çay & Oolong Çayı & Siyah Çay \\
\hline \multicolumn{3}{|c|}{ Toplam fenolik madde (mg/g.k.m) } & $83.61 \pm 3.48$ & $05.16 \pm 4.95$ & - & $61.94 \pm 3.70$ \\
\hline \multicolumn{3}{|c|}{ Toplam flavon ve flavonol glikozitler (mg/g, k.m) } & $15.32 \pm 1.12$ & $20.56 \pm 0.46$ & $3.03-5.01$ & $10.99 \pm 1.39$ \\
\hline \multicolumn{3}{|c|}{ Toplam kataşinler (mg/g, k.m) } & - & $0.20-28.30$ & $187.84-279.43$ & $2.68-2.77$ \\
\hline \multicolumn{3}{|c|}{ Epigallokateşin gallat (mg/g, k.m) } & $19.58 \pm 7.06$ & $44.71 \pm 1.13$ & - & $3.86 \pm 0.13$ \\
\hline \multicolumn{3}{|c|}{ Gallokateşin (mg/g, k.m) } & $3.28 \pm 1.60$ & $6.17 \pm 0.65$ & - & $1.02 \pm 0.02$ \\
\hline \multicolumn{3}{|c|}{ Epigallokateşin (mg/g, k.m) } & $2.31 \pm 0.36$ & $39.44 \pm 0.90$ & $0.71-78.82$ & $3.33 \pm 0.66$ \\
\hline \multicolumn{3}{|c|}{ Epikateşin gallat (mg/g, k.m) } & - & $14.19-27.80$ & - & $2.09-46.28$ \\
\hline \multicolumn{3}{|c|}{ Epikateşin (mg/g, k.m) } & $1.54 \pm 0.43$ & $6.99 \pm 0.08$ & - & $1.27 \pm 0.1$ \\
\hline \multicolumn{3}{|c|}{ Gallokateşin gallat (mg/g, k.m) } & - & $2.60-48.02$ & $0.09-58.89$ & 49.54-60.92 \\
\hline \multicolumn{3}{|c|}{ Gallik asit (mg/g, k.m) } & $2.01 \pm 1.5$ & - & - & $2.38 \pm 0.14$ \\
\hline \multicolumn{3}{|c|}{ Tearubugin } & - & - & - & 59.4 \\
\hline \multicolumn{3}{|l|}{ Kafein } & $35.83 \pm 3.89$ & $17.37 \pm 0.27$ & $3.14-83.20$ & $22.34 \pm 0.88$ \\
\hline \multicolumn{7}{|l|}{ Antioksidan aktivite } \\
\hline \multicolumn{3}{|l|}{ ABTS ( $\mu \mathrm{M}$ TE/g) } & $8.45 \pm 0.11$ & $9.7 \pm 0.03$ & - & $4.35 \pm 0.05$ \\
\hline \multicolumn{3}{|c|}{ DPPH (mg numune/mL EC50) } & $0.282 \pm 0.10$ & $0.073 \pm 0.02$ & & $0.509 \pm 0.04$ \\
\hline \multicolumn{7}{|c|}{ Çizelge 2. Çayın sağlık üzerinde koruyucu etkisi (Formica and Regelson, 1995; Hertog ve ark., 1993; Hodgson ve ark., 2002) } \\
\hline $\begin{array}{l}\text { Kardiovasküler } \\
\text { hastalıklar }\end{array}$ & Kanser & \multicolumn{2}{|c|}{ Diyabet } & Obezite & $\begin{array}{l}\text { Sinir sistemi } \\
\text { hastalıkları }\end{array}$ & $\begin{array}{l}\text { Enfeksiyon } \\
\text { hastalıklar }\end{array}$ \\
\hline \multirow{2}{*}{$\begin{array}{l}\text { Anti-trombojenik } \\
\text { etki } \\
\text { Hipotansif aktivite }\end{array}$} & Anti-mutajenik etki & \multicolumn{2}{|c|}{ Anti-diyabetik etki } & $\begin{array}{l}\text { Lipid } \\
\text { metabolizması } \\
\text { üzerinde etkisi }\end{array}$ & Stres üzerine etkisi & $\begin{array}{l}\text { Antimikrobiyal } \\
\text { etki }\end{array}$ \\
\hline & Antikarsinojenik etki & \multicolumn{2}{|c|}{ Hipoglisemik etki } & Lipaz inhibisyonu & Uyarıcı etkisi & Anti-fungal etki \\
\hline $\begin{array}{l}\text { Anti-inflamatuar } \\
\text { etki }\end{array}$ & Anti-inflamatuar etki & \multicolumn{2}{|c|}{$\begin{array}{l}\text { İnsülin direnci } \\
\text { üzerine etkisi }\end{array}$} & Termojenik etki & Anti-depresan etki & Anti-viral etki \\
\hline \multirow[t]{3}{*}{ Antioksidan aktivite } & DNA hasarının azaltması & \multicolumn{2}{|c|}{$\begin{array}{l}\text { Antioksidan } \\
\text { aktivite }\end{array}$} & $\begin{array}{l}\text { İştah üzerine } \\
\text { etkisi }\end{array}$ & \multicolumn{2}{|l|}{ Antioksidan etki } \\
\hline & Antioksidan aktivite & \multicolumn{3}{|c|}{$\begin{array}{l}\text { Hipokolesterolemik } \\
\text { etki }\end{array}$} & & \\
\hline & Anti-anjiyojenik etki & \multicolumn{3}{|c|}{$\begin{array}{l}\text { Lipolitik ve } \\
\text { anti-adipojenik etki }\end{array}$} & & \\
\hline
\end{tabular}


Yapılan birçok çalışma çaylarda bulunan flavonoidlerin KDH'ları üzerinde koruyucu etkileri olduğunu göstermiştir. Hertog ve ark. (1993) 805 yaşlı birey ile yürüttükleri çalışmada bireylere çay, elma ve soğan tüketimleri sorulmuş ve günlük flavonoid tüketimleri 29 mg'dan fazla olan bireylerin kardiyovasküler hastalık risklerinin \%68 daha düşük olduğunu saptamışlardır. Hollanda'da 4807 kişinin katıldığı çalışmada günde 3 fincan fazla siyah çay tüketen bireylerin, hiç çay tüketmeyenlere oranla kalp krizi riskinin \%68 daha az olduğu bulunmuştur (Cooper ve ark., 2005). Yeşil çayın arteriyosklerozu geciktirdiğini destekleyen hayvan ve insan üzerinde denenmiş birçok çalışma vardır. Fareler üzerinde yapılmış çalışmada çayın EGCG arteriyosklerotik lezyonlarının gelişimini engellediğini fakat var olan lezyonlara etki etmediği bulunmuştur (Cheng, 2006).

Yapılan epidemiyolojik çalışmalarda çayın hipertansif etkisi olduğuna dair farklı sonuçlar elde edilmiştir. Yang ve ark. (2004) çayın hipertansiyon üzerinde koruyucu etkisi araştırdığı çalışmasında; 1 yıldan fazla süreyle günde $120 \mathrm{ml}$ yeşil veya oolong çayı tüketen bireylerin hipertansiyon riskinin önemli derece azalttığını bulmuşlardır.

Mennen ve ark. (2003) Fransa'da yürüttükleri kardiyovasküler risk faktörleri ve çay tüketimi arasındaki ilişkiyi inceleyen çalışmada; kadınlarda günlük tüketilen çay miktarı arttıkça total kolesterol, serum trigiliserid, bel-kalça oranı ve açlık kan şekeri düzeylerinin düştüğünü bulmuşlardır. Hodgson (2008) düzenli çay tüketiminin etkilerini araştırma amacıyla; toplam 4 hafta boyunca 21 kişiye her gün düzenli olarak 5 fincan $(800 \mathrm{ml}$ ) siyah çay tüketmeleri istenmiştir. Çalışmanın sonunda endotel disfonksiyonun gelişimi ve kardiyovasküler hastalık riskini azalttığı bildirilmiştir. Hirata ve ark. (2004) siyah çay ve kafeinin koroner sirkülasyonundaki etkilerini araştırdığı çalışmada; siyah çayın koroner akışkanlığını arttırdığını göstermişlerdir.

Koutelidakis ve ark. (2009) beyaz çay ekstresini beş gün boyunca verildiği farelerde, sadece plazma antioksidan kapasitesini değil, aynı zamanda kalp ve akciğerler gibi organlarında da kapasitenin arttığı bildirmiştir. Çayın bileşiminde bulunan kuersetin ve L-teanin hayvanlarda ve insanlarda kan basıncını düşürür ve böylece kardiyovasküler hastalıkların gelişmesi riskini azaltır (Tijburg ve ark., 1997).

Gardner ve ark. (2007) 3430 kişi üzerinden yaptıkları çalışmada günde $480 \mathrm{ml}$ çay tüketen bireylerin Koroner Kalp Hastalığı (KKH) riskini azalttığı, çay miktarı ve koruyucu etkisi arasında ilişki olduğu bildirilmiştir. Vinson ve ark. (2004) Amerika'da yürüttüğü çalışmada günde 5 bardak çay tüketimi bireylerde kolesterolün düştüğünü ve kalp krizi riskinin azaldığını rapor etmiştir.

Inflamasyonun vasküler hastalıkların başlangıcında ve ilerlemesinde önemli bir rol oynamaktadır. In vitro çalışmalar çay ve diğer gıdalarda bulunan flavonoidlerin anti-inflamatuar etki ettiğini göstermektedir. Böylece flavonoidler, vasküler hastalıkların oluşumuna karşı koruyucu etki gösterir (Sies ve ark., 2005)

Aşırı trombosit aktivasyonu, agregasyon ve pıhtılaşmanın artmasına neden olur. Bu da miyokard enfarktüsüne ve inmeye neden olan trombozun önemli bir nedenlerinden biridir. In vitro çalışmalar, izole flavonoidlerin trombosit agregasyonunu ve trombosit aktivasyonunun işaretleyicilerini azaltabildiğini göstermiştir (Rein ve ark., 2000). Insanlar üzerinde yapılan bir dizi çalışmada flavonoid açısından zengin yiyecek ve içeceklerin trombosit fonksiyonu üzerindeki etkilerini araştırılmıştır (Hodgson, 2008). Çalışma, 4 hafta boyunca düzenli çay tüketiminin, trombosit aktivasyonunun bir göstergesi olan dolaşımdaki p-selektin konsantrasyonlarında bir azalmaya neden olduğunu göstermiştir (Hodgson ve ark., 2002).

\section{SONUÇ}

Çay, yaklaşık 5000 bin yıllık bir tarihi olduğu düşünülen, hayatımızın bir parçası olmuş ve kültür haline gelmiş bir içecektir. İçerdiği etkin maddelerin sağlığımız üzerindeki olumlu etkileri yadsınamaz bir gerçektir. Tarih boyunca çay tüketim biçimi ve yapılan epidemiyolojik çalışmalar durumu destekleri niteliktedir. Çay yapısında özellikle kimyasal birçok bileşik bulunduran bir bitkidir. Bunlar başlıca alkoloidler, uçucu organik bileşikler, polifenoller ve eser miktarda elementlerdir. Çayda polifenoller başlıca flavanoller (kateşinler) ve flavonoller olarak bulunmaktadır. Polifenolik bileşikler serbest radikalleri temizler ve hücre içi enzimlerin aktivitesini arttırırlar. Çay üretim sürecinde uygulanan yöntem, çevresel, genetik, coğrafi faktörlerine bağlı olarak çayın içeriği ve antioksidan aktivitesi farklılık göstermektedir. Ele aldığımız siyah çay, yeşil çay, oolong çayı ve beyaz çayın içerdiği fenolik maddelerden dolayı kardiyovasküler hastalıklara karşı koruyucu etki gösterdiği bilimsel çalışmalarla bildirilmiştir. Sonuç olarak çay, içeriği sebebiyle iyi bir antioksidan kaynağıdır. Yetişkinlerde günde 2-3 litre sıvı tüketimi önerilmektedir. Bunun başlıca kaynağı su olmakla birlikte günde 5-7 fincan (800-1120 mL) çay tüketilmesi önerilmektedir.

\section{KAYNAKLAR}

Altuğ T, Elmacı Y (1998) Gıdalarda doğal olarak bulunan lezzet bileşenleri. Gıda Kimyası, Hacettepe Ünv. Yayınları 453-86. Ankara

Atalay D, Erge S (2017) Determination Of some physical and chemical properties of white, green and black teas (Camellia sinensis). GIDA/The Journal of Food 42.

Carloni P, Luca T, Lucia P, Tiziana B, Chisomo C, Alexander K, Elisabetta D (2013) Antioxidant activity of white, green and black tea obtained from the same tea cultivar. Food research international 53: 900-08.

Chang K (2015) World tea production and trade: Current and future development. A publication by the Food 
and Agricultural Organization of the United Nations, Rome. Available online at www. fao. org (date accessed 29 May 2016).

Cheng T (2006) All teas are not created equal: the Chinese green tea and cardiovascular health. International journal of cardiology 108: 301-08.

Cooper R, James M, Dorothy M (2005) Medicinal benefits of green tea: Part I. Review of noncancer health benefits. Journal of Alternative \& Complementary Medicine 11: 521-28.

ÇAYKUR (2011) Beyaz çayin tarihçesi ve üretim teknolojisi. Accessed 04.04.2018.

Çelik F (2006) Çay (Camellia sinensis); içeriği, sağlık üzerindeki koruyucu etkisi ve önerilen tüketimi. Türkiye Klinikleri Journal of Medical Sciences 26: 64248.

Formica JV, Regelson W (1995) Review of the biology of quercetin and related bioflavonoids. Food and Chemical Toxicology 33: 1061-80.

Gardner E, Ruxton C, Leeds (2007) Black tea-helpful or harmful? A review of the evidence. European Journal of Clinical Nutrition 61: 3.

Graham N (1992) Green tea composition, consumption, and polyphenol chemistry. Preventive Medicine 21: 33450.

Haslam E (2003) Thoughts on thearubigins. Phytochemistry 64: 61-73.

Henning M, Claudia F, Hyun L, Arthur A, Vay L, David H (2003) Catechin content of 18 teas and a green tea extract supplement correlates with the antioxidant capacity. Nutrition and Cancer 45: 226-35.

Hertog M, Edith J, Daan K, Hollman P, Katan M (1993) Dietary antioxidant flavonoids and risk of coronary heart disease: the Zutphen Elderly Study. The Lancet 342: 1007-11.

Hilal Y, Engelhardt U (2007) Characterisation of white teaComparison to green and black tea. Journal für Verbraucherschutz und Lebensmittelsicherheit 2: 414-21.

Hirata K, Kenei S, Hiroyuki W, Ryo O, Koutaro T, Minoru Y, Shunichi H, Junichi $Y$ (2004) Black tea increases coronary flow velocity reserve in healthy male subjects. American Journal of Cardiology 93: 1384-88.

Hodgson M (2008) Tea flavonoids and cardiovascular disease. Asia Pacific Journal of Clinical Nutrition 17: 288-90.

Hodgson M, Puddey P, Valerie B, Gerald W, Lawrence B (2002) Regular ingestion of black tea improves brachial artery vasodilator function. Clinical Science 102: 195-201.

Hodgson M, Ian B, Kevin D, Valerie B, Trevor A, Rima Abu-A, Lawrence J (2000) Acute effects of ingestion of black and green tea on lipoprotein oxidation. The American journal of Clinical Nutrition 71: 1103-07.

Hollman P, Edith J, Martijn B (1999) Tea flavonols in cardiovascular disease and cancer epidemiology. Proceedings of the Society for experimental Biology and Medicine 220: 198-202.
POLAT E, KARAMAN AD, ÖĞÜT S

TC (2019) Annual Bullettin of Statistics (2019). International Tea Committee (ITC), London,UK, p. 48-50.

Katiyar A, Zhi Y, Ashok K, Hasan M (1992) Epigallocatechin3-gallate in Camellia sinensis leaves from Himalayan region of Sikkim: Inhibitory effects against biochemical events and tumor initiation in sencar mouse skin. Nutr. Cancer 18(1):73-83.

Katiyar K, Hasan M (1997) Inhibition of phorbol ester tumor promoter 12-O-tetradecanoylphorbol-13-acetatecaused inflammatory responses in SENCAR mouse skin by black tea polyphenols. Carcinogenesis 18: 1911-16.

Koutelidakis E, Konstantina A, Mauro S, Charalambos P, Michael K, Monia P, Maria K (2009) Green tea, white tea, and Pelargonium purpureum increase the antioxidant capacity of plasma and some organs in mice. Nutrition 25: 453-58.

Langley E, Simon C (2000) Antioxidant potential of green and black tea determined using the ferric reducing power (FRAP) assay. International journal of food sciences and nutrition 51: 181-88.

Leung L, Yalun S, Ruoyun C, Zesheng Z, Yu H, Zhen C (2001)Theaflavins in black tea and catechins in green tea are equally effective antioxidants. The Journal of nutrition 131: 2248-51.

Mahmood T, Naveed A, Barkat K (2010) The morphology, characteristics, and medicinal properties of Camellia sinensis tea. Journal of Medicinal Plants Research 4: 2028-33.

McKay L, Blumberg J (2002) The role of tea in human health: an update. Journal of the American College of Nutrition 21: 1-13.

Mennen I, Denis M, Pilar G, Paul P, Sandrine B, Eric B, Michèle $M$, Claire $F$, Serge $H$ (2003) Tea consumption and cardiovascular risk in the SU. VI. MAX Study: Are life-style factors important? Nutrition Research 23: 879-90.

Namita P, Rawat M, Kumar J (2012) Camellia sinensis (green tea): A review. Global Journal of Pharmacology 6: 5259.

Rein D, Teresa G, Debra P, Ted W, Harold H, Robert G, Carl L (2000) Cocoa and wine polyphenols modulate platelet activation and function. The Journal of Nutrition 130: 2120-26.

Santana R, Gilberto S, Gayle A, Adams A, Cynthia P, ShiauYin W, Roderick H (2001) Potent antimutagenic activity of white tea in comparison with green tea in the Salmonella assay. Mutation Research/Genetic Toxicology and Environmental Mutagenesis 495: 6174.

Sarı F (2010) Çay işlemede teanin miktarinin değişimi. Doktora Tezi, Ankara Üniversitesi.

Sies H, Tankred S, Christian H, Malte K (2005) Cocoa polyphenols and inflammatory mediators. The American journal of clinical nutrition 81: 304S-12S.

Sumpio E, Alfredo C, David W, Feng Q, Quan C (2006) Green tea, the "Asian paradox," and cardiovascular disease. Journal of the American College of Surgeons 202: 81325. 
Tijburg L, Mattern T, Folts J, Weisgerber U, Katan M (1997) Tea flavonoids and cardiovascular diseases: a review. Critical Reviews in Food Science \& Nutrition 37: 77185.

Tosun i (2012) Çay ve çay fenoliklerinin antioksidan aktivitesi. Anadolu Tarım Bilimleri Dergisi 20: 78-83.

Üstün Ç, Demirci N (2013) Çay bitkisinin (Camellia sinensis L.) tarihsel gelişimi ve tibbi açidan değerlendirilmesi. Bildiriler Kitabı: 175.

Vinson A, Karolyn T, Nancy W (2004) Green and black teas inhibit atherosclerosis by lipid, antioxidant, and fibrinolytic mechanisms. Journal of agricultural and food chemistry 52: 3661-65.

Yang S, Landau M (2000) Effects of tea consumption on nutrition and health. The Journal of nutrition 130: 2409-12.

Yang Y, Lu F, Wu J, Wu C, Chang C (2004) The protective effect of habitual tea consumption on hypertension. Archives of internal medicine 164: 1534-40. 